\title{
A Further Analysis on the Welfare Effects of Illegal Immigration
}

\author{
Eriko Hiraiwa and Makoto Tawada \\ Nagoya University
}

\begin{abstract}
This paper re-examines Yoshida's analysis (1993 and 1996) and draws further aspects of economic welfare within Bond and Chen's framework (1987). We show that an increase in fine that a firm pays could be a better policy than an intensification of internal inspection enforcement from a welfare point of view. We also show that, in the case where capital is internationally mobile, if technologies are different between countries and labor-capital intensity is larger in the home country than in the foreign, the impact of an increase in enforcement on the factor prices is opposite to that of Bond and Chen (1987). We also enlarge the welfare effect of an increase in enforcement more precisely in the case of capital movement.
\end{abstract}

- JEL Classifications: F22

- Key words: Illegal immigration, National welfare, Capital mobility

\section{Introduction}

In the analysis of economic impacts caused by illegal immigration, Ethier (1986) proposed a clear framework and investigated the economic effects of border and internal enforcements to control a level of illegal immigration. Based on Ethier's idea, the analysis was further developed by Bond and Chen (1987). Moreover, Yoshida (1993 and 1996) extended Bond and Chen's analysis to examine impact of the illegal immigration control on national welfare.

The main purpose of this paper is to re-examine the Yoshida's work and draw

\footnotetext{
*Corresponding address: Professor Makoto Tawada School of Economics Nagoya University Furo-cho, Chikusa-ku Nagoya, 464-8601, Japan E-mail: mtawada@soec.nagoya-u.ac.jp (O)2003-Center for International Economics, Sejong Institution, All Rights Reserved.
} 
further aspects focused on internal inspection policy as a way of enforcement within the Bond and Chen's framework. While an effect of increases in inspection effort on welfare of each country has been examined by Yoshida (1993), we will develop his analysis by discussing how the conclusions are altered if an authority increases fine that a firm pays for hiring illegal foreign workers as a penalty instead of choosing a policy of increases in internal inspection enforcement to reduce the level of illegal immigrants. In addition, in the case when capital is internationally mobile, we re-examine the existing analysis under the condition that technologies are different between countries.

In section 2, we present the model and the basic results obtained so far. Section 3 deals with the welfare analysis. Then the analysis is further extended to the case of international capital mobility in Section 4. Section 5 is devoted to conclusions.

\section{The Model}

Following Bond and Chen's model, here we consider a two-country model where two factors, capital and labor, are combined in each country to produce a single output. Both countries are assumed to have constant supplies of capital and labor, where labor is supposed to be internationally mobile.

Suppose first that capital is immobile between countries. It is assumed that the home country is capital-abundant and the foreign country is labor-abundant. Under labor immobility, therefore, the home wage rate is supposed to exceed the foreign wage rate in equilibrium. Thus the wage differential attracts the foreign workers to work in the home country.

The home country is assumed not to receive foreign workers legally so that the immigrants in the home country are treated as illegal workers. To prevent this illegal entry, the government of home country chooses an internal enforcement policy against firms that hire the illegal workers. Let $E$ be the level of expenditure on enforcement and $p$ be the probability of detection that is an increasing function of $E$, so that $p=p(E)$ with $\mathrm{p}(0)$ and $p^{\prime}(\mathrm{E})>0$ for $0^{\circ}-p(E)<1$, where $p^{\prime}$ shows the derivative of $p$. (Hereafter, a function with prime means the derivative of that function.) We simply assume that all economic agents are risk neutral. Then the illegal migration adjusts so as to equate the home wage, w, and the cost of employing an illegal worker that is the foreign wage, $w^{*}$, plus the expected fine, so that we have, in equilibrium, 


$$
w=w^{*}+p(E)_{z},
$$

where $z$ denotes the fine a firm pays for each illegal worker as penalty. Each country produces a single output via a neoclassical linearly homogenous production function. The production function for the home country can be written as $F(K, L) \equiv K f(\lambda)$ where $\lambda \equiv L / K$, and $L$ and $K$ are, respectively, the amounts of labor and capital employed in the home country. In equilibrium we must have

$$
\begin{gathered}
f^{\prime}(\lambda)=w, \\
f(\lambda)-\lambda w=r,
\end{gathered}
$$

where $r$ stands for the rental of capital in the home country. From (2), we have

$$
\lambda=\lambda(w),
$$

where $\lambda^{\prime}=1 / f^{\prime \prime}<0$.

In the foreign country, perfect competition and cost minimization also yield the following relations,

$$
\begin{gathered}
f^{*}\left(\lambda^{*}\right)-\lambda * w^{*}=r^{*}, \\
\lambda^{*}=\lambda^{*}\left(w^{*}\right),
\end{gathered}
$$

where $\lambda^{*}$ is the labor-capital ratio of the foreign country and $r^{*}$ stands for the rental of capital in the foreign country.

The equilibrium conditions in the home and the foreign factor markets are,

$$
\begin{gathered}
(1-a) \bar{K} \lambda\left(w^{*}+p(E) z\right)=\bar{L}, \\
\lambda *\left(w^{*}\right) \bar{K}^{*}+a \lambda\left(w^{*}+p(E) z\right) \bar{K}=\bar{L}^{*},
\end{gathered}
$$

respectively, where $a \equiv I(\bar{L}+I)$ is the fraction of the illegal workers in the home country, $I$ is the level of immigration, $\bar{L}$ and $\bar{K}$ are, respectively, the fixed supplies of labor and capital in the home country, and $\overline{L^{*}}$ and $\overline{K^{*}}$ are, respectively, the fixed supplies of labor and capital in the foreign country.

Totally differentiating (7) and (8) and solving for the effects of an increase in E yields, 


$$
\begin{gathered}
d w^{*} / d E=-\bar{K} \lambda \bar{K} \lambda^{\prime} p^{\prime} z / \Delta<0, \\
d a / d E=(1-a) \bar{K} p^{\prime} \bar{K}{ }^{\prime} \lambda^{\prime} \lambda *^{\prime} z / \Delta<0,
\end{gathered}
$$

where $\Delta \equiv K \lambda\left(\bar{K} \lambda^{\prime}+\bar{K}^{*} \lambda^{* \prime}\right)<0$. From (1), (3) to (6) and the definition of $a$, we obtain

$$
\begin{gathered}
d I / d E=\bar{K}^{2} \lambda \bar{K} * \lambda^{\prime} \lambda *^{\prime} p^{\prime} z / \Delta<0, \\
d w / d E=\bar{K} * \lambda * \bar{K} \lambda p^{\prime} z / \Delta<0, \\
d r / d E=-\lambda d w / d E<0, \\
d r * d d E=-\lambda * d w^{*} / d E>0 .
\end{gathered}
$$

In view of (9) and (12) to (14), an increase in enforcement causes two opposite effects on the wage and the rental, where home capital and foreign labor are harmed. Moreover, (10) and (11) show that the absolute amount as well as percentage of illegal workers in the home country declines. These results are intuitively explained as follows. An increase in enforcement yields a decrease in the amount of illegal migrants. Through this fall in $I$, the home labor/capital ratio decreases while that of the foreign increases. Therefore the home wage and rental rises and falls, respectively. And those of the foreign change to the opposite directions.

\section{Welfare Analysis}

In this section, country welfare is investigated by observing how the level of enforcement maximizes national income of the home country. ${ }^{1}$ National income in the home country can be expressed as

$$
Y=w \bar{L}+r \bar{K}+(z-v) p(E) I-E,
$$

\footnotetext{
${ }^{1}$ Throughout of this paper, a welfare level is measured by a level of national income. This is because the utility of each economic agent is expressed by a function of one final good and income transfer is assumed to be properly carried out by the government so as to make every agent better off if national income increases. Thus we only focus on the level of national income for the welfare analysis.
} 
where $v$ is the real resource cost for deporting an illegal worker to the foreign country who is caught by the internal enforcement. Differentiating (15) with respect to $E$ gives $^{2}$

$$
d Y / d E=-I d w^{*} / d E+(z-v) p(E) d I / d E-\left(v p^{\prime} I+1\right) .
$$

The first term of the RHS in (16) is positive but the second and the third terms are shown to be negative, so that the sign of $d Y / d E$ cannot be determined uniquely. ${ }^{3}$

If the enforcement cost, $E$, is large enough for the level of immigration, $I$, to be nil, then it holds that $d Y /(d E)=(z-v) p(E) d I / d E-1<0$, which means that an increase in the level of enforcement has a negative effect on national welfare. Evaluating (16) at $E=0$, we have $p(E)=0$ and hence

$$
d Y / d E=-I d w^{*} / d E-\left(v p^{\prime} I+1\right),
$$

again, whose sign is ambiguous. In this case, if the level of illegal immigration is sufficiently large and there are no costs of deportation, it is possible that $d Y / d E$ is positive. Suppose that $\bar{E}$ is the level of $E$ such that all illegal immigrants are swept away to their country. Then an optimal level of $E$ might exist somewhere between 0 and $\bar{E}$. However, if $d Y / d E$ is negative at $E=0$, the optimal level of $E$ might be a corner solution such that $E=0$.

As to welfare of the foreign country, it is shown as

$$
Y^{*}=w^{*}\left(\bar{L}^{*}-I\right)+r^{*} \bar{K}^{*}+w^{*}+I=w^{*} L^{*}+r^{*} K^{*} .
$$

Differentiation of (17) with respect to $E$ brings forth of

\footnotetext{
${ }^{2}(15)$ can be expressed as $Y=w \bar{L}+r \bar{K}+\left(w-w^{*}-v p(E)\right) I-E$.

Differentiating this expression with respect to $E$, we obtain $d Y / d E=(\bar{L}+I) d w / d E+\bar{K} d r / d E-I d w^{*} / d E+\left(w-w^{*}-v p(E)\right) d I / d E-\left(v p^{\prime} I+1\right)$ $=((\bar{L}+I)-\lambda \bar{K}) d w / d E-I d w^{*} / d E+(z-v) p(E) d I / d E-\left(v p^{\prime} I+1\right)$ $=-I d w^{*} / d E+(z-v) p(E) d I / d E-\left(v p^{\prime} I+1\right)$, from the fact that $\lambda=(\bar{L}+I) / \bar{K}$.

${ }^{3}$ Yoshida(1993) discussed that $d Y / d E$ must be positive if the sum of last two terms in absolute value exceeds the first term. This argument, however, only insists that the condition for $d Y / d E$ to be positive is that the RHS of (16) is positive.
} 


$$
d Y * / d E=\bar{L}^{*} d w * / d E+\bar{K}^{*} d r * / d E=I d w * / d E<0
$$

Finally, we see the world welfare measured as $Y+Y^{*}$. We have

$$
Y+Y^{*}=w \bar{L}+r \bar{K}+(z-v) p(E) I-E+w \bar{L}^{*}+r^{*} \bar{K}^{*}
$$

Differentiate (19) with respect to $E$. Then we have

$$
d\left(Y+Y^{*}\right) /(d E)=(z-v) p(E) d I / d E-\left(v p^{\prime} I+1\right)<0,
$$

under the condition that $z-v>0 .{ }^{4}$

The discussion we have made so far is based on a framework within which the home authority considers an inflow movement of immigrants as an illegal action and expends enforcement costs setting a legal barrier to limit their inflow to the home country. In the formula $w=w^{*}+p(E) z$, a pressure against labor inflow is measured by the level of $p(E) z$. That corresponds to the case in which the home government controls an incentive for a foreign worker to migrate to the home country by imposing a tax on importing labor. In the present model, the authority does not have free access to information on who is illegal, so that the home country must make an effort with its expenditure $E$ to identify illegal workers. To raise barriers to prevent illegal workers flowing into the home country an increase in $p(E)$ is necessary. An increase in $p(E)$ through an increase in $E$ apparently means that the national income will decrease by the direct amount of the increasing inspection cost. It must be favorable for the home country welfare if it can shut off illegal immigration without any resource expenditure. In this sense, increasing a fine that a firm pays against hiring each illegal worker could be a better policy in order to restrict labor inflow from the foreign country. Apparently, this corresponds to the case that the home country raises a level of tax imposed on imported labor. Therefore it must be attractive for the home country to choose $\mathrm{z}$ as a variable factor instead of $\mathrm{E}$ for controlling illegal employment.

Let be at any given and positive level. Effects of an increase of fine $z$ on each factor of $w^{*}, a, I, w, r$, and $r^{*}$ are given by the same analysis in (9) (14), so that we obtain the same sign to the previous ones. (This is established by the fact that

\footnotetext{
${ }^{4}$ Though Yoshida (1993) evaluates (20) to be negative at the level of $E=0$, it is obvious that (20) must be negative at any level of $E$ if $z-v>0$.
} 
$p^{\prime} z$ in the numerator of (9) (14) is replaced by $p$.) How an increase in $\mathrm{z}$ affects the national income of home, abroad, and the world can be seen as,

$$
\begin{gathered}
d Y / d z=-I d w * / d z+(z-v) P d I / d z, \\
d Y^{*} / d z=I d w^{*} / d z, \\
d\left(Y+Y^{*}\right) / d z=(z-v) p d I / d z,
\end{gathered}
$$

respectively.

It is immediate from (21) that an increase in $z$ gives a favorable effect to the home welfare if $0<z<v$ Therefore, for any given positive $E$, it must be optimal to impose a positive level of $z$ on the firms for employing illegal workers. ${ }^{5}$

As to the foreign country, (22) shows that an increase in fine always reduces the welfare. However, as seen in (23), the world welfare improves if $z<v$ and deteriorates if $v<z$.

\section{Capital Mobility}

We have discussed various effects of enforcement policies under the case in which capital is immobile. Now we consider how results are altered if capital is mobile, following Bond and Chen's framework (1987).

Bond and Chen (1987) and Yoshida (1996) consider that technologies are identical in the two countries. But here we continue to assume that technologies are allowed to differ between countries. This leads to the case that simultaneous movement of both capital and labor can occur in order to reach the equilibrium where $r$ is the same level as $r^{*}$. Therefore, we do not have to introduce a tax on home capital located in the foreign country.

Using the comparative static analysis following Bond and Chen (1987), we

\footnotetext{
${ }^{5}$ Bond and Chen(1987) points out that increasing the level of penalty would increase the incentive to bribe officials responsible for catching illegal workers, requiring increases in monitoring of these officials. If we introduce monitoring cost function $M(z)$ that is the increasing function of the level of $z$, national income of the home country can be expressed as

$Y=w \bar{L}+r \bar{K}+(z-v) p(E) 1-E-M(z)$.

How an increase in (through the incentive for bribery) affects the home income is, instead of (21), $d Y / d z=-I d w^{*} / d z+(z-v) p d I / d z-M^{\prime}(z)$

Based on this equation, we can extend our discussion on the welfare to the case where the monitoring cost is necessary.
} 
obtain the three-equation system;

$$
\begin{gathered}
{\left[\begin{array}{ccc}
\lambda *-\lambda & 0 & 0 \\
\left(\bar{K}-K_{F}\right)(1-a) \lambda^{\prime} & -\left(\bar{K}-K_{F}\right) \lambda-(1-a) \lambda \\
\left(\bar{K}^{*}+K_{F}\right) \lambda *^{\prime}+a \lambda^{\prime}\left(\bar{K}-K_{F}\right) & \left(\bar{K}-K_{F}\right) \lambda & \lambda *-a \lambda
\end{array}\right]\left[\begin{array}{c}
d w^{*} \\
d a \\
d K_{F}
\end{array}\right]} \\
{\left[\begin{array}{c}
\lambda p^{\prime} z d E \\
-\left(\bar{K}-K_{F}\right)(1-a) \lambda^{\prime} p^{\prime} z d E \\
-\left(\bar{K}-K_{F}\right) a \lambda^{\prime} p^{\prime} z d E
\end{array}\right],}
\end{gathered}
$$

where $K_{F}$ is the amount of home capital located in the foreign country. Solving this system yields,

$$
\begin{gathered}
d w^{*} / d E=\lambda p^{\prime} z /(\lambda *-\lambda)>(<) 0 \text { as } \lambda *>(<) \lambda, \\
d a / d E=p^{\prime} z\left[-\lambda *^{2}(1-a)\left(\bar{K}-K_{F}\right) \lambda^{\prime}-\lambda^{2}(1-a)\left(\bar{K}^{*}+K_{F}\right) \lambda *^{\prime}\right] / \Delta<0, \\
d K_{F} / d E=p^{\prime} z\left[\lambda * \lambda\left(\bar{K}-K_{F}\right)^{2} \lambda^{\prime}+\left(\bar{K}-K_{F}\right)\left(\bar{K}^{*}+K_{F}\right) \lambda^{2} \lambda *^{\prime}\right] / \Delta<0, \\
d w / d E=d w^{*} / d E+p^{\prime} z>(<) 0 \text { as } \lambda *>(<) \lambda, \\
d r / d E=-\lambda d w / d E<(>) 0 \text { as } \lambda *>(<) \lambda, \\
d r^{*} / d E=-\lambda * d w^{*} / d E<(>) 0 \text { as } \lambda *>(<) \lambda,
\end{gathered}
$$

where the determinant $\Delta \equiv-(\lambda *-\lambda)^{2}\left(\bar{K}-K_{F}\right) \lambda$ is negative. In the case where $\lambda *>\lambda$, these (25) (30) are basically same to the results obtained by Bond and Chen(1987). As they point out, an increase in expenditure on enforcement raises the foreign wage because the increase in expected penalties causes capital to move form the home to the foreign and the home capital prefers purchasing foreign labor legally. The overall effect falls on capital because the home country is the capitalintensive location for production. Therefore the overall effect rises on wage. Conversely, if $\lambda *<\lambda$, the foreign country is the capital-intensive location. So a shift in each factor reward is reversal in direction.

Now using these results we can examine effects on welfare of each country. The welfare of home country is shown to be, 


$$
Y=w \bar{L}+r \bar{K}+(z-v) p(E) I+\left(r^{*}-r\right) K_{F}-E .
$$

Differentiation of (31) with respect to $E$ yields,

$$
\begin{gathered}
d Y / d E=\left(r^{*}-r\right) d K_{F} / d E-I d w * / d E-\lambda * K_{F} d w * / d E \\
+p(z-v) d I / d E-\left(v p^{\prime} I+1\right) .
\end{gathered}
$$

In the case where $\lambda *>\lambda$, the terms of the RHS in (32) except the first one are all negative in sign. Therefore, considering the equilibrium condition that $r^{*}=r$, (32) shows that the intensification of enforcement unambiguously reduces the national welfare if $z=v$. Since Bond and Chen (1987) and Yoshida (1996) assumed that there is a tax on capital located in the foreign country, it must hold that $r^{*}>r$ in equilibrium. Hence, the sign of $d Y / d E$ cannot be determined. In the case where $\lambda *<\lambda$, the sign of $d Y / d E$ is ambiguous, so that there is a possibility of a rise in the welfare by an increase in $E$. Of another interest would be the effect of the intensification of enforcement on the welfare of the foreign country and the world as shown, respectively, by

$$
\begin{gathered}
d Y^{*} / d E=\left[\bar{L}^{*}-\bar{K}^{*}\left(\bar{L}^{*}-I\right)\left(\bar{K}^{*}+K_{F}\right)\right] d w^{*} / d E, \\
d\left(Y+Y^{*}\right) / d E=\left(r^{*}-r\right) d k_{F} / d E+p(z-v) d I / d E-\left(v p^{\prime} I+1\right) .
\end{gathered}
$$

It is evident from (33) that the intensification of enforcement results in a favorable (unfavorable) effect on the foreign country if $\lambda *>(<) \lambda$. We further proceed to the world welfare. In the case where a capital tax is imposed as in Bond and Chen (1987) and Yoshida (1996), it is possible for the sign of (34) to be positive. But if there is no capital tax, the first term of the RHS in (34) vanishes. Thus (34) is unambiguously negative in sign provided that $z-v>0$. It follows that an increase in enforcement reduces the world welfare. If $z<v$, the sign of $d\left(\mathrm{Y}^{*}+\mathrm{Y}\right) /$ $\mathrm{dE}$ is again indeterminate.

We finally consider the case in which capital is mobile between countries and examine how an increase in fine a firm pays changes the level of welfare. Suppose that $E(>0)$ is given at a certain level. In the case of a change in $\mathrm{z}$, a similar comparative static analysis can be made. The equation system for the analysis is the same as (24) but replacing $p^{\prime} z d E$ with $p d z$. Thus we conclude that the effects of an increase in $z$ on $w, w^{*}, a, K_{F}, r$ and $r^{*}$ are the same as before in quality.

The effects on welfare of each country and the world can be observed by 
Table 1

\begin{tabular}{|c|c|c|c|c|c|c|c|c|c|}
\hline & I & $\mathrm{K}_{\mathrm{F}}$ & $\mathrm{W}$ & $\mathrm{r}$ & $w^{*}$ & $r^{*}$ & $Y$ & $\mathrm{Y}^{*}$ & $\mathrm{Y}+\mathrm{Y}^{*}$ \\
\hline $\begin{array}{l}\text { Bond and Chen } \\
\text { Yoshida }(E)\end{array}$ & - & + & + & - & + & - & ? & + & ? \\
\hline $\begin{array}{c}\lambda^{*}>\lambda \\
(E \text { and } z)\end{array}$ & - & + & + & - & + & - & $\begin{array}{c}- \\
(z>v)\end{array}$ & + & $\begin{array}{l}-(E) \\
(z>v)\end{array}$ \\
\hline $\begin{array}{c}\lambda^{*}>\lambda \\
(E \text { and } z)\end{array}$ & - & + & - & + & - & + & $\begin{array}{l}\text { ?(E) } \\
+(z) \\
(z<v)\end{array}$ & - & $\begin{array}{c}?(E) \\
(z<v) \\
+(z) \\
(z<v)\end{array}$ \\
\hline
\end{tabular}

$$
\begin{aligned}
& d Y / d z=\left(r^{*}-r\right) d K_{F} / d z-I d w * / d z-\lambda * K_{F} d w * / d z+p(z-v) d I / d z<(>) 0, \\
& \text { if } \lambda *>(<) \lambda \text { and } z>(<) v \text {, } \\
& d Y^{*} / d z=\left[\bar{L}^{*}-\bar{K}^{*}\left(\bar{L}^{*}-I\right)\left(\bar{K}^{*}+K_{F}\right)\right] d w^{*} / d z>(<) 0, \text { if } z>(<) v \\
& d\left(Y+Y^{*}\right) / d z=\left(r^{*}-r\right) d K_{F} / d z+p(z-v) d I / d z<(>) 0, \text { if } z>(<) v, \\
& \text { since } r=r^{*} \text {. }
\end{aligned}
$$

We summarize the results obtained in this section as Table 1.

\section{Conclusions and Remarks}

We have extended the discussion proposed by Yoshida (1993 and 1996) where he examined the national and foreign welfare in Bond and Chen's framework (1987). This paper has drawn further aspects of effects of an increase in penalty on national and foreign welfare, which has not been considered in Bond and Chen (1987) and Yoshida (1993 and 1996).

Although an intensification of enforcement needs extra inspection cost, an increase in the penalty can be realized without any expenditure for the authority. Hence the latter policy could be better in order to restrict labor inflow from the foreign county. In fact, we have observed from (16) and (21) that an increase in penalty is more likely to be effective in increasing national welfare than an intensification of enforcement. The expressions of (32) and (35) indicated that this conclusion is also true even if capital is mobile internationally.

Finally, we have put aside the assumption made by Bond and Chen (1987) that 
technologies are the same in both countries. This allows a return to capital to be equal between both countries in equilibrium under capital as well as labor movement. By taking this into account, we have analyzed how an increase in enforcement will affect each country's factor prices and welfare. Then we have reached different results from Bond and Chen (1987) and Yoshida (1996) as shown in the table of the previous section. It has been shown that our results on the welfare analysis are more transparent than theirs as a whole. Moreover, if the labor-capital equilibrium ratio is greater in the home country than in the foreign country, the responses of factor prices are completely reversal and the welfare responses also tend to be opposite to theirs.

Here two remarks may be in order ${ }^{6}$. One remark is that our attention has been paid to the internal enforcement. To control the level of immigration border enforcement may be another interesting measure. In fact Ohta(1990) studied this case in Bond and Chen's framework and obtained similar results to ours. Bandopadhyay and Bandopadhyay (1998) also analyzed the effects of the border enforcement on illegal immigration and factor rewards but in a different framework. Still their results are basically similar to ours. They did not investigate the welfare aspect.

The other remark is that our model is a full employment model. So an interesting extension is to see welfare effects by enforcement policies in the presence of unemployment. In this context, Djajic(1987) made a comparative static analysis in a model based on the Ramaswami model but with HarrisTodaro's unemployment aspect. He concentrated on the analysis of how the level of a minimum wage, the amount of a fixed capital and so on influences the endogenous variables such as the stock of immigrants and the enforcement spending rather than the level of welfare. Thus the welfare analysis in Djajic's framework is a future topic. Recently Yabuuchi(2002) also tackled this topic under the existence of the Harris-Todaro type of unemployment. Concerning the welfare analysis he obtained the result that various subsidies raise the level of welfare and a rise in the probability of detection lowers it. But he did not give any welfare analysis with respect to the enforcement policies rigorously.

\section{Acknowdgements}

We are deeply indebted to Professors M.C. Kemp, K. Kondoh, M. Kunisaki,

\footnotetext{
${ }^{6}$ These two remarks are suggested by the referee.
} 
H.Ohta and S.Yabuuchi and a referee for valuble comments and suggestions.

Received 7 Deccember 2001, Accepted 9 July 2002

\section{References}

Bandyopadhyay, S. and S.C.Bandyopadhyay (1998), "Illegal immigration: a supply side analysis", Journal of Development Economics, 57, 343-360.

Bond, Eric W. and Tain-Jy Chen (1987), "The Welfare Effects of Illegal Immigration", Journal of International Economics, 23, 315-328.

Diajic, S. (1987), "Illegal Aliens, Unemployment and Immigration Policy”, Journal of Development Economics, 25, 235-249.

Ethier, Wilfred J. (1986), "Illegal Immigration”, American Economic Review, 76, 56-71. Ohta, H. (1990), "Illegal foreign labor and economic welfare" (in Japanese), Annual Report on Economics and Business Administration, Kobe University 40, 141-159.

Yabuuchi, S. (2002), "Illegal Immigration, Informal Sector and Development Policies in a Dual Economy", Arthanitil (1\&2), forthcoming

Yashida, C. (1993), “The Global welfane of Illegal Immigration : A Note". Indian Economic Review, 28, 111-115.

Yoshida, C. (1996), "The Global welfare of Illegal Immigration in the Presence of Capital Mobility”, Journal of Economic Integration, 11, 554-565.

\section{Appendix}

In our present model where both labor and capital can move internationally and technologies are different between countries, graphical examples of equilibrium are shown according to the factor intensity ranking between countries.

(i) The case where $\lambda *>\lambda$ in equilibrium. In Figure $1, \lambda_{0}$ and $\lambda_{0} *$ are initial

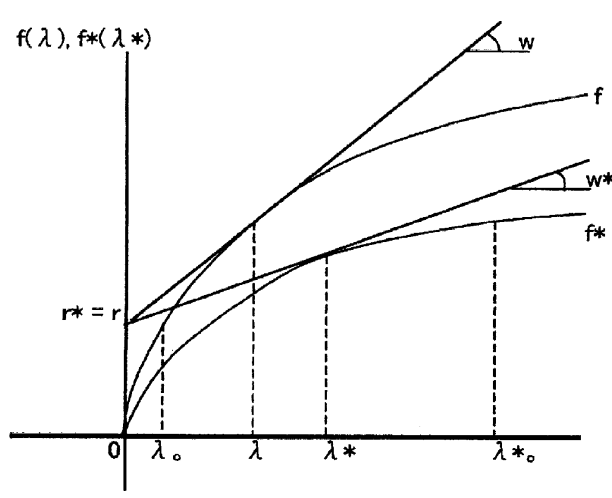

Figure 1

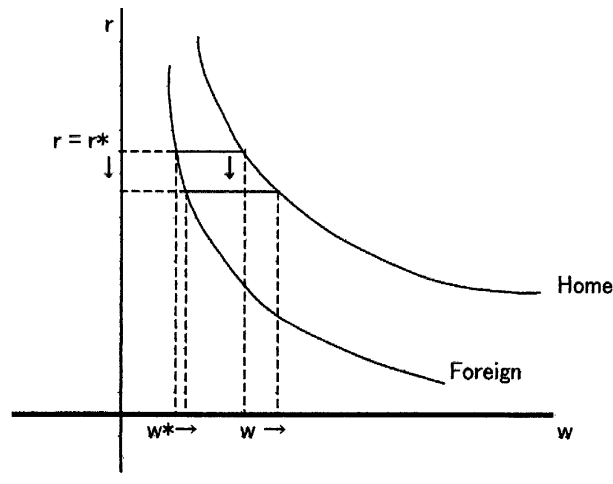

Figure 2 
labor-capital ratios of the home and the foreign countries, respectively. After factor movements, $\lambda_{0}$ and $\lambda_{0} *$ shift to those of equilibrium levels $\lambda$ and $\lambda *$, respectively. In view of (2) and (3), $d r / d w=-\lambda$. This is also true in the foreign country. Hence, based on Figure 1, we have Figure 2 where the factor price relations of both countries are shown. The intensification of the enforcement enlarges the gap between $w$ and $w^{*}$. Hence, $r\left(=r^{*}\right)$ falls and $w$ and $w^{*}$ rise.

(ii) The case where $\lambda *<\lambda$ in equilibrium. The similar argument to (i) applies with Figure 3 and 4.

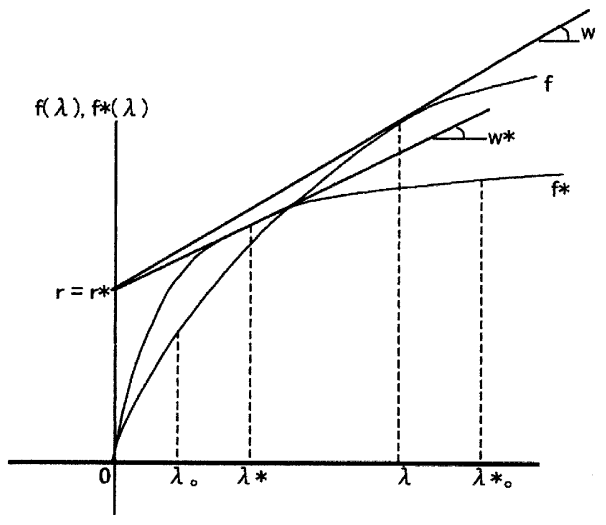

Figure 3

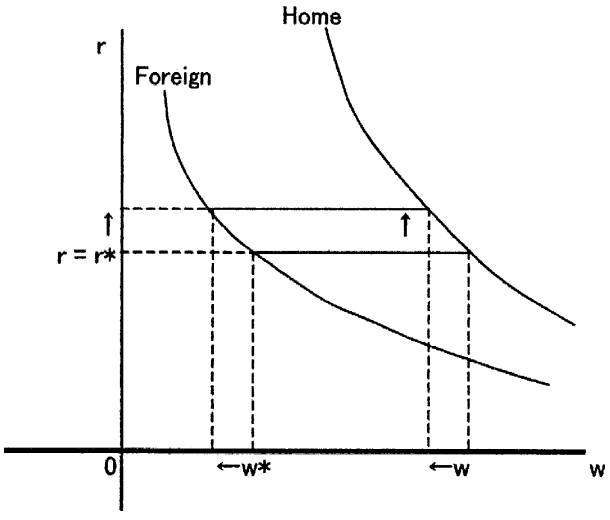

Figure 4 